\title{
Marginal abatement cost curves and the optimal timing of mitigation measures
}

\author{
Adrien Vogt-Schilb ${ }^{1, *}$, Stéphane Hallegatte ${ }^{2}$ \\ ${ }^{1}$ CIRED, Paris, France. \\ ${ }^{2}$ The World Bank, Sustainable Development Network, Washington D.C., USA
}

\begin{abstract}
Decision makers facing abatement targets need to decide which abatement measures to implement, and in which order. Measure-explicit marginal abatement cost curves depict the cost and abating potential of available mitigation options. Using a simple intertemporal optimization model, we demonstrate why this information is not sufficient to design emission reduction strategies. Because the measures required to achieve ambitious emission reductions cannot be implemented overnight, the optimal strategy to reach a short-term target depends on longer-term targets. For instance, the best strategy to achieve European's $-20 \%$ by 2020 target may be to implement some expensive, high-potential, and long-to-implement options required to meet the $-75 \%$ by 2050 target. Using just the cheapest abatement options to reach the 2020 target can create a carbonintensive lock-in and make the 2050 target too expensive to reach. Designing mitigation policies requires information on the speed at which various measures to curb greenhouse gas emissions can be implemented, in addition to the information on the costs and potential of such measures provided by marginal abatement cost curves.
\end{abstract}

\section{Highlights}

- Classification of existing Marginal Abatement Cost Curves (MACC) - MACCs do not provide separated data on the speed at which measures can be implemented $>$ Optimal measures to reach a short-term target depend on longer-term targets Unique carbon price or aggregated emission-reduction target may be insufficient Room for short-term sectoral policies if agents are myopic or governments cannot commit

Keywords: climate change mitigation; dynamic efficiency; sectoral policies JEL classification: L98; Q48; Q54; Q58

This version: November 21st, 2013

\footnotetext{
* Corresponding author

Email addresses: vogt@centre-cired.fr (Adrien Vogt-Schilb), shallegatte@worldbank.org (Stéphane Hallegatte)
} 


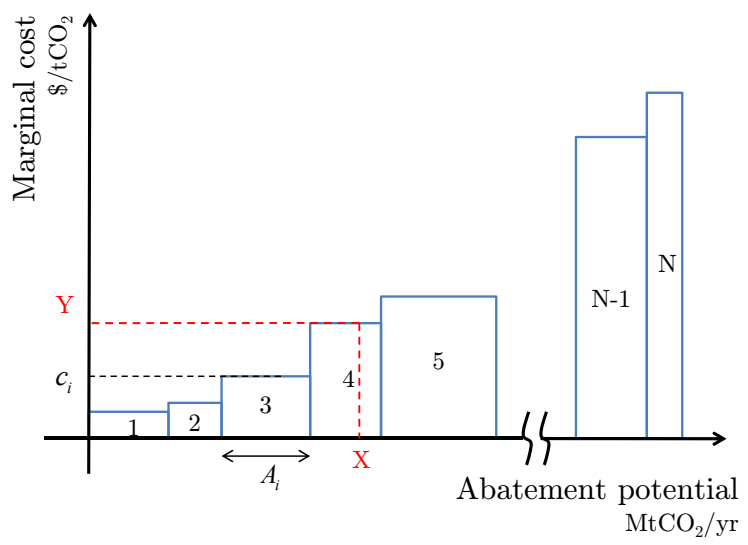

Figure 1: A measure-explicit MACC exhibits $N$ abatement options ranked from the least to the most expensive. Each option $i$ is characterized by their abatement potential $A_{i}$ and their marginal abatement $\operatorname{cost} c_{i}$. This curves stands for a given date $\mathrm{T}$. We explain why the optimal mitigation strategy to reach a target $\mathrm{X}$ at $\mathrm{T}$ is not necessarily to implement exclusively the measures 1 to 4 cheaper than $\mathrm{Y}$ (where $\mathrm{Y}$ is the marginal abatement cost corresponding to $\mathrm{X}$ on the curve).

\section{Introduction}

To design the best policies to cope with climate change, decision-makers need information about the options for reducing greenhouse gas (GHG) emissions. Such information has been provided in many ways, including through measureexplicit marginal abatement cost curves (MACCs). We call measure-explicit $M A C C s$ the curves that represent information on abatement costs and potentials for a set of mitigation measures. Measures include changing technologies, notably in the transport, housing and power sectors, but also non-technological options such as waste recycling and management of land use and forest. These MACCs are usually constructed for a specific country or region, and for a specific date. They report abatement potentials as a function of the abatement cost, ranking mitigation options from the least to the most expensive (Fig. 1).

Decision makers who face an emission-reduction target need to decide which abatement options to implement, and following which schedule. They can misinterpret measure-explicit MAC curves as abatement supply curves. According to this interpretation, the optimal behavior to meet an abatement target (e.g, bringing back GHG emissions at their 1990 level by 2020) is to build a MAC curve for this date, and implement only the cheapest options that allow the target to be met (e.g., DECC, 2011, Fig 17, p. 52).

In this paper, we explain why decision makers need to distinguish available abatement measures using their costs, abating potential, and the time it takes to implement them. Indeed, the high-abating potential options required to meet ambitious emission-reduction targets cannot be implemented overnight. Therefore, the optimal set of measures to reach a short-term target depends on the measures required to meet longer-term targets and on the speed at which these measures can take effect.

We thus propose a new way for reporting information on emission-reduction options to the general public and decision-makers. Reports could display assess- 
ments of the cost of each option, the abating potential or carbon intensity of each option, and the speed at which each option can be implemented - taking into account the required accumulation of human and physical capital. While some MACCs factor in all this information, none provides data on these three dimensions separately.

We first contribute a classification of existing MAC curves (Section 2). Then, we build a simple model that can compute the optimal timing of GHG emissions reductions (choice across time) along with the optimal dispatch of the reduction burden (choice across abatement measures) from this three dimensions (Section 3). We use it in Section 4 with an objective in terms of cumulative emissions over a long period, a so-called carbon budget, reportedly a good proxy for climate change. We show that it make sense to implement the more expensive options before exhausting the whole potential of the cheapest options. We turn in Section 5 to objectives expressed in terms of aggregate abatement at one point in time, closer to the actual practices. In that case, it can be preferable to start implementing the most expensive options before cheap ones, if their potential is large and their inertia is great (Section 5.1). Finally, we explain in Section 5.2 how the optimal short-term strategy depends on the long-term emission objective. This means that MACCs should not be used as supply curves when choosing the optimal strategy to reach short-term emission targets.

\section{Overview of existing marginal abatement cost curves}

The term "MAC curve" refers in the literature to various curves, constructed in various ways. Here, we distinguish continuous MAC curves and measureexplicit MAC curves. We then distinguish full-potential measure-explicit MACCs and achievable-potential measure-explicit MACCs.

\subsection{Continuous vs. measure-explicit MAC curves}

Continuous MAC curves depict the aggregate shadow cost of an emission target against the stringency of this target. They do not depict particular mitigation measures. The existing literature builds this type of MACCs from Integrated Assessment Models (IAM). It has for instance emphasized that the cost of reducing GHG emissions inside an economy depends on external factors such as energy prices or climate policies decided abroad (Klepper and Peterson, 2006; Kuik et al., 2009; Morris et al., 2011).

In this paper we take the perspective of a decision maker who faces an exogenous abatement target and needs to decide which emission-reduction options to implement, and in which order. Continuous MACCs are out of the scope of this paper. We focus on measure-explicit MAC curves that represent information on abatement costs and potentials for a set of mitigation measures (Fig. 1).

Measure-explicit MACCs have recently reached a wide public, when McKinsey and Company published an assessment of the cost and potentials in the United States (Enkvist et al., 2007) and at the global scale (McKinsey, 2009). These curves are increasingly used to inform policymakers: McKinsey currently lists 15 MAC curves in its website, the World Bank has assessed reduction potentials in many countries in the form of MACCs (ESMAP, 2012), and Sweeney and Weyant (2008) have proposed such a MACC for California. Other examples include the MACCs developed by the Wuppertal Institute (2006), and by 
Bloomberg (2010). Their usage goes beyond climate mitigation: for instance, similar depictions have been used to describe available options to reduce energy consumption (e.g., Jackson, 1991), waste production (Beaumont and Tinch, 2004) and water consumption (McKinsey, 2009).

Recent research has identified - and proposed solutions for - methodological issues when building measure-explicit MAC curves (Kesicki and Ekins, 2012); this has allowed to enhance the reporting of abatement costs and potentials. A first issue relates to uncertainty when assessing future costs - it can be addressed by presenting ranges of costs and potentials instead of best-guest estimates (IPCC, 2007, SPM6 p.11). A second issue is that MACCs do not depict the interaction between different measures (e.g, promoting electric vehicles and green electricity together would allow to save more GHG than the sum of the two isolated abatement measures), even if they are built taking these interactions into account (Kesicki, 2012b). Kesicki and Ekins (2012) identify other shortcomings, like the fact that MACCs frequently assess project or technological costs only, excluding institutional barriers, transaction costs and non-monetary costs. In contrast, we focus in this paper on how to use MAC curves, that is on how they can help to design optimal emission-reduction strategies.

\subsection{Full potential vs. achievable potential measure-explicit MAC curves}

While similar in appearance, two types of measure-explicit MAC curves should be distinguished, depending on their implicit definition of the abating potential of a measure.

The full-potential approach gives information on how much GHG could be saved if the measure was used at his technical maximum. It is calculated against a reference or baseline technology, taking into account the carbon intensity and imperfect substitutability of different technologies. For instance, this approach takes into account that an Electric Vehicle (EV) does not emit any GHG (e.g. saves $140 \mathrm{gCO}_{2} / \mathrm{km}$ compared to the average new vehicle sold in Europe in 2010) but that all passenger vehicles cannot be replaced by EVs due to limited driving range. This approach does not take into account any dynamic aspect.

Among others, Rubin et al. (1992) used this approach. For instance, they assess the potential of nuclear power (in the US) as the quantity of GHG that would be saved if nuclear replaced all the fossil fuel capacity that was used for base load and intermediate load operation in 1989, and find $1500 \mathrm{MtCO}_{2} / \mathrm{yr}$ (Rubin et al., 1992, Table 3, footnote j). More recently, Wächter (2013) built a MAC curve for Austria based on the same approach, using 2008 data.

We call the other approach the achievable-potential approach. It seems to have been popularized by McKinsey. Achievable-potential measure-explicit MAC curves have a prospective dimension, as they are built for a date in the future. This approach takes into account that large-scale diffusion of new technologies can take up to decades (Grübler et al., 1999). In this context, the abating potential of a technology assesses the abatement that could be achieved with such a technology if it was implemented at a given speed (McKinsey, 2009, Exhibit 1). For instance, this approach takes into account that even ambitious fiscal incentives in favor of electric vehicles would induce a limited increase of EV sales, resulting in a limited share of EVs by 2020 or 2030. The achievablepotential by a given date mixes the information on the full potential and the slow diffusion process, and is therefore lower than the full potential described above. 
A MACC built this way is the one by Sweeney and Weyant (2008): they find for instance that solar photovoltaic power can only save $0.8 \mathrm{MtCO}_{2} / \mathrm{yr}$ in California by 2020. They also distinguish the abating potential of industrial combined heat and power achievable thanks to price incentives and the potential that can be reached after an "aggressive growth" (Table 11 page 50). As IAMs account for slow technological diffusion (Wilson et al., 2013), they can be used to produce achievable-potential measure-explicit MACCs. One example is the MACC built by Kesicki (2012a) for the UK transport sector by 2030 .

In the following we show the value of combining the two approaches, i.e. how the full-potential and the implementation speed, reported separately, can be used to decide which options to implement, and in which order, to comply with exogenous emission targets. We propose a methodology to do so, based on three information pieces per measure - its cost, full potential, and implementation speed - and a simple intertemporal optimization model.

\section{Model}

A social planner controls GHG abatement from an emission baseline, by spending money and time on a set of options described by their cost, full abatement potential, and implementation speed. We do not incorporate more realistic but complex dynamics, such as sectoral interactions or crowding-out effects on investment.

\subsection{GHG emissions}

There are $N$ abatement options, indexed by $i$. The model is run on a period that goes from 2000 to 2050 with a time step, $\Delta t$, of 3 months. At each time step $t$, emissions are computed from the baseline emissions $E_{t}^{r e f}$ and the abatement $a_{i, t}$ achieved with each measure $i$ at time $t$.

$$
e_{t}=E_{t}^{r e f}-\sum_{i=1}^{N} a_{i, t}
$$

The cumulative emissions $M_{t}$ are then computed as the sum of emissions.

$$
M_{t}=e_{t} \cdot \Delta t+M_{t-\Delta t}
$$

\subsection{Potentials, costs and inertia}

Each measure is described by three figures. First, each measure $i$ has a maximum abating potential $A_{i}$, expressed in avoided annual emissions, in $\mathrm{MtCO}_{2} / \mathrm{yr}$. For instance, switching to more efficient thermal engines for passenger vehicles may not save more than a fraction of GHG emissions associated with private mobility. In full-potential measure-explicit MACCs, this potential is represented by the width of the rectangles (see Fig. 1).

$$
a_{i, t} \leq A_{i}
$$

Second, each measure $i$ is qualified with a constant abatement cost $c_{i}$ - the heights in Fig. 1. Here, we also assume that abatement costs are independent of 
cumulative abatement and time. ${ }^{1}$ Abatement $a_{i, t}$ achieved thanks to measure $i$ at time $t$ has a cost $I_{i, t}$ which reads.

$$
I_{i, t}=a_{i, t} \cdot c_{i}
$$

Third, a given amount of abatement requires a non-negative amount of time for its implementation. This is modeled as a constant maximum speed $v_{i}$, (in $\mathrm{MtCO}_{2} / \mathrm{yr} / \mathrm{yr}$ ), assumed to be independent of the financial cost of the measure ${ }^{2}$ : achievable abatement at time $t$ directly depend on already achieved abatement at time $t-\Delta t .^{3}$

$$
a_{i, t} \leq a_{i, t-\Delta t}+v_{i} \cdot \Delta t
$$

These growth constraints may come from any bottleneck such as (i) availability of skilled workers, (ii) availability of productive capacities, (iii) incompressible institutional requirements, (iv) emissions being embedded in long-lived capital, or (v) requirement for knowledge accumulation before technologies spread.

Issues (i) and (ii) could be overcome by training workers or redirecting unemployed workers and unused capital; but training and redirecting are measures per se and cannot be done overnight either. The issue of institutional or organizational delays is well documented (World Bank and International Finance Corporation, 2013). Reducing them is also a measure per se, and takes time. The fourth point is related to capital vintages and turnover: if one sees emissions as embedded in capital (Davis et al., 2010; Guivarch and Hallegatte, 2011), decarbonization cannot be faster than capital turnover, except by wasting valuable productive capital through premature replacement (Lecocq et al., 1998; Lecuyer and Vogt-Schilb, 2013; Rozenberg et al., 2013). Concerning (v), Mansfield (1998), and Agarwal and Bayus (2002) have found that research and development is typically carried out from several years to few decades before new technologies experience market uptake.

As noted in section 2.2, MAC curves built for a date in the future $T$ frequently provide an achievable potential, not a full potential. In our framework, the achievable potential $\tilde{A}_{i}$ is linked to the full potential $A_{i}$ and the implementation speed $v_{i}$.

$$
\tilde{A}_{i}=\min \left(v_{i} \cdot T, A_{i}\right)
$$

We can also define the implementation time as $A_{i} / v_{i}$, the ratio of the abatement potentials over the maximum speed.

\subsection{Social planner objectives}

The objective is to achieve a climate-related target while minimizing abatement costs. The decision maker minimizes $C$, the total present cost of abate-

\footnotetext{
${ }^{1}$ On the effect of learning-by-doing, see del Rio Gonzalez (2008) and Meunier and Finon (2013).

${ }^{2}$ Note that abatement is expressed in $\mathrm{MtCO}_{2} / \mathrm{yr}$

${ }^{3}$ The initial abatement is assumed to be null $\left(a_{i, 0}=0\right)$. This is done without loss of generality: if the initial abatement is not null, a new abating potential $A_{i}^{\prime}$ can be redefined as the potential beyond what is already achieved $A_{i}^{\prime}=A_{i}-a_{i, 0}$
} 


\begin{tabular}{lcccc}
\hline & & & Cheap & Deep \\
\hline Marginal Abatement Cost & $c$ & $\$ / \mathrm{tCO}_{2}$ & 30 & 60 \\
Full potential & $A$ & $\mathrm{GtCO}_{2} / \mathrm{yr}$ & 1.5 & 3.5 \\
Speed & $v$ & $\mathrm{MtCO}_{2} / \mathrm{yr}^{2}$ & 60 & 50 \\
\hline
\end{tabular}

Table 1: Numerical assumptions

ment, discounted at rate $r$ over the period.

$$
C=\sum_{t=T_{0}}^{T} \sum_{i=1}^{N} \frac{I_{i, t}}{(1+r)^{t \cdot \Delta t}}
$$

Theoretically, a benevolent social planner can control GHG emissions in order to equalize the marginal costs of mitigation and adaptation in a cost-benefit approach. Because of uncertainty surrounding both climate response to a change in GHG emissions and adaptation costs, and because decisions are made at national instead of global scale, it is common to adopt a cost-effectiveness approach (Ambrosi et al., 2003). In our model, this can be done by constraining cumulative emissions $M_{t}$ to remain below a given carbon budget $M_{o b j}$.

$$
M_{t} \leq M_{o b j}
$$

Cumulative emissions can be used as proxies for climate change (Allen et al., 2009; Matthews et al., 2009).

In practice, however, governments and other public agencies frequently provide objectives for given points in time. For instance, the EU has the objective of cutting its emissions by $20 \%$ of 1990 levels by $2020 .^{4}$ In our model, these objectives can be implemented by defining a set of milestones indexed by $m$, and by constraining emissions at each milestone.

$$
e_{t_{m}} \leq E_{m}^{o b j}
$$

\subsection{Numerical values}

For illustrative purpose, we assume a MAC containing only two contrasted measures $(N=2)$, labeled cheap and deep. Cheap has a lower abatement cost than deep, but also a lower abatement potential (Table 1). Cheap could represent for instance the measure of switching energy sources in buildings, and deep could represent the retrofitting of these buildings. In the auto industry, cheap could represent the energy efficiency gains in the internal combustion engines and deep switching to other energy sources, such as electricity or hydrogen.

In the absence of reliable data, we assume that it takes 70 years to implement the whole potential of deep, while cheap only requires 25 years. They lead to values for $v$ of respectively $50 \mathrm{MtCO}_{2} / \mathrm{yr}^{2}$ and $60 \mathrm{MtCO}_{2} / \mathrm{yr}^{2}$. We use $r=$ $5 \% / \mathrm{yr}$ as the discount rate. These values are not meant to represent accurately concrete sectors of the economy, even though they do not differ much from

\footnotetext{
${ }^{4}$ It is also common to adopt intensity objectives, as the efficiency standards in the auto industry. Our model may be used with existing intensity MACCs (IEA, 2009, p. 37).
} 

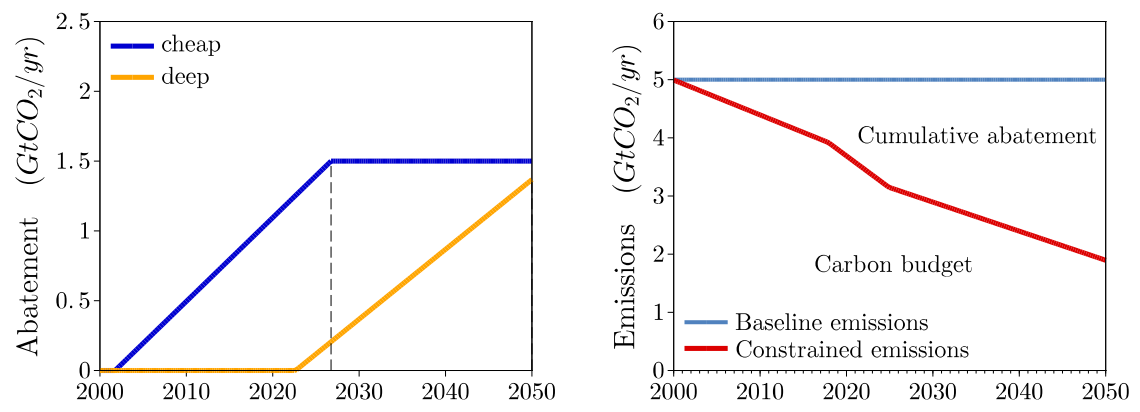

Figure 2: Left: Optimal abatement strategy to limit cumulative emissions below $175 \mathrm{GtCO}_{2}$ between 2000 and 2050. Inertia and discounting mean that deep has to enter before the potential of cheap has been exhausted. Right: curves represent emissions in the baseline and in the constrained simulation; in-between areas represent the cumulative abatement and the carbon budget in the constrained simulation.

the two sectors modeled by Lecocq et al. (1998). We assume constant baseline emissions, that is $E_{t}^{r e f}=5 \mathrm{GtCO}_{2} / \mathrm{yr}$ (close to contemporaneous European GHG emissions). We use these values to carry out illustrative experiments, which help draw more general conclusions.

We solve this simple model using a linear programing algorithm provided by GAMS (Brook et al., 1988). The source code also uses Scilab (Scilab Consortium, 2011). Code and data are available on the corresponding author's web page. Results may be verified using the spreadsheet model provided on the corresponding author's web page.

\section{Optimal schedule under a cumulative carbon budget}

In this section, we investigate the optimal abatement pathway when using a carbon budget, i.e. with full flexibility on when to reduce emissions (Eq. 8). We test a range of carbon budgets $\left(M_{o b j}\right)$, and assess the consequence on the optimal reduction pathway.

\subsection{Using expensive options before exhausting the potential of cheap ones}

Figure 2 shows the optimal strategy for maintaining cumulative emission below $175 \mathrm{GtCO}_{2}$ over the 2000-2050 period. This value is used for illustrative purpose, and will allow us to make some comparisons with subsequent simulations (in Section 5).

The abatement paths (figure 2, left panel) have triangular or trapezoidal shapes; this shows that one of the inertia (Eq. 5) or maximum potential (Eq. 3) constraint is always binding. The cumulative abatement corresponds to the area between baseline emissions and emissions in the constrained run (figure 2, right panel). In this case, the intuitive ranking of abatement measures is respected: the social planner starts by implementing cheap before deep. However, she does not use the whole potential of cheap before starting using deep. Deep enters in 2023 while cheap does not reach its full potential before 2027. A more stringent objective would force deep to start even earlier (see below). 


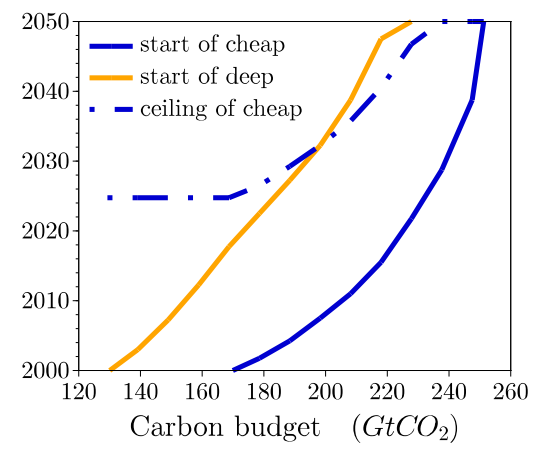

Figure 3: Entry date and ceiling date of each abatement measure as a function of the carbon budget. Lower carbon budgets, on the left, correspond to tighter climate objectives and require more abatement. Start of deep/cheap is the date when the respective measure begins to be implemented; the ceiling date is the date when the abating potential is exhausted.

The optimal implementation strategy does not follow a merit order in which the whole potential of the cheapest solutions is used before more expensive solutions are introduced.

A more systematic analysis using a range of carbon budgets (Fig. 3) confirms that for any objective it is never preferable to implement the expensive deep before cheap. It also shows that if the objective is stringent enough (about $195 \mathrm{GtCO}_{2}$ ), deep has to begin before the whole potential of cheap has been exploited - the implementation is not sequential. And if the carbon budget is even more stringent (about $130 \mathrm{GtCO}_{2}$ ), deep is forced to start in 2000, at the same time as cheap.

\subsection{Expensive options may be useful even when cheaper ones appear sufficient}

Let us analyze a case in which the carbon budget is not very stringent, e.g. $210 \mathrm{GtCO}_{2}$. This translates into cumulative abatement of $45 \mathrm{GtCO}_{2}$ over the period. ${ }^{5}$ Cheap has a cumulative abatement potential of more than $55 \mathrm{GtCO}_{2} \cdot{ }^{6}$ It is then possible to achieve the abatement objective by implementing only cheap. An intuitive strategy could be to focus on cheap and to not implement deep. Our simulations show that this is not the optimal strategy, because there is a trade-off between (i) implementing only the cheapest solutions, but starting early to give them enough time to reach the objective; (ii) delaying abatement in order to save present value (thanks to the discounting), but undertaking both cheap and deep to be more aggressive later and reach the objective in spite of the delayed action.

In our simulations (Fig. 3), the optimal strategy to meet a (lax) $210 \mathrm{GtCO}_{2}$ carbon budget is to implement deep from year 2040, which makes it possible not

\footnotetext{
${ }^{5}$ Cumulative emissions in the baseline amount to $5 \mathrm{Gt} / \mathrm{yr}$ during 51 years, that is $255 \mathrm{Gt}$.

6 Its annual abatement potential is $1.5 \mathrm{Gt} / \mathrm{yr}$ and takes 25 years to implement in full (see Table 1); adding the cumulated potential during the take-off phase $(25 \mathrm{yr} \times 1.5 \mathrm{Gt} / \mathrm{yr}) / 2$ and the potential when annual abatement have reached their maximum value $25 \mathrm{yr} \times 1.5 \mathrm{Gt} / \mathrm{yr}$ gives a total of $56.25 \mathrm{Gt}$.
} 


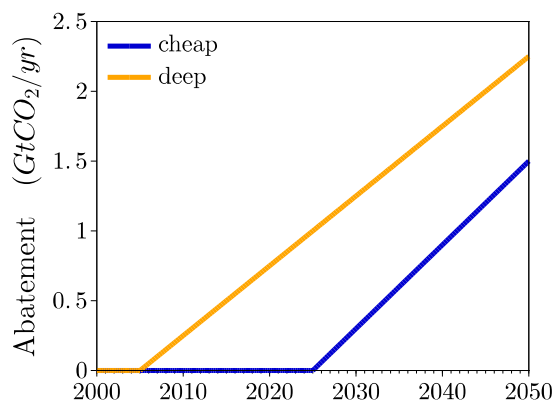

Figure 4: Optimal abatement pathways to achieve ambitious abatement $\left(3.75 \mathrm{GtCO}_{2} / \mathrm{yr}\right)$ in 2050 . The expensive option with large abatement potential is implemented before the cheaper option.

to implement cheap before 2011 (for a strategy starting in 2000). The additional cost of using deep is more than compensated by the delay on implementing cheap. In other words, the optimal strategy uses an expensive measure even when a cheaper measure is sufficient to reach the objective.

\section{Optimal abatement pathways with annual emission targets}

Commitments in terms of carbon budget are difficult to enforce: there is an incentive for decision-makers to delay investments and efforts beyond their mandate. Alternative policies include the definition of emission targets at one or several points in time. In the next two sections, we assume that commitments are made in terms of abatement levels at different points in time.

The cumulative-emissions constraint (Eq. 8) is thus excluded from the model, and we include the emission constraint with a single milestone $\left(m \in\{1\}, t_{1}=\right.$ $2050)$ and test various emission objectives ( $E_{1}^{o b j}$ in Eq. 9). We find that the shape of the optimal mitigation strategy depends on the stringency of the emission target.

\subsection{Implementing expensive options before cheap ones}

Figure 4 shows the optimal abatement pathway for achieving an ambitious reduction of $75 \%$ of emissions in 2050 . In this case, the optimal strategy is to start by implementing the most expensive option before the cheapest (i.e., deep starts before cheap).

Indeed, the emission objective translates into abatement by $3.75 \mathrm{GtCO}_{2} / \mathrm{yr}$ in 2050, which cannot be achieved by implementing cheap alone. The cheapest way to achieve this objective in 2050 is to use cheap to abate as much GHG emissions as possible, i.e. $1.5 \mathrm{GtCO}_{2} / \mathrm{yr}$. Because cheap cannot penetrate faster than $60 \mathrm{MtCO}_{2} / \mathrm{yr}^{2}$, it has to enter in 2026 . Then $2.25 \mathrm{GtCO}_{2} / \mathrm{yr}$ remain to be abated with deep by 2050. To do so, deep has to enter as soon as 2006, 20 years before cheap.

The $75 \%$ reduction in emissions leads to cumulative emissions of $175 \mathrm{GtCO}_{2}$, 


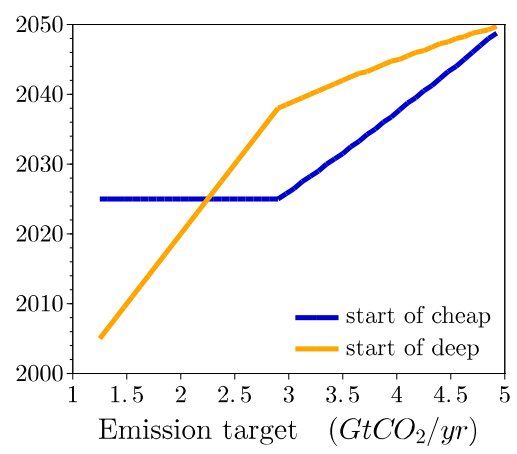

Figure 5: Entry date of each measure as a function of emission objective for 2050. For ambitious emission targets (below $2.25 \mathrm{GtCO}_{2} / \mathrm{yr}$ ), the expensive option with large abatement potential is implemented before the cheaper option.

and is thus comparable to the simulation proposed in Section $4.1 .^{7}$ Compared to the carbon-budget simulation, this emission-targets simulation leads to start cheap later and deep sooner. Short-term abatement are lower - in 2020, they amount to $750 \mathrm{MtCO}_{2} / \mathrm{yr}$ under an emission target, against $1.3 \mathrm{GtCO}_{2} / \mathrm{yr}$ under a carbon budget - but long-term abatement are higher.

The loss of when-flexibility eventually raises the present cost of abatement, from $390 \mathrm{G} \$$ to $630 \mathrm{G} \$$ when the carbon budget is replaced by an emission target. ${ }^{8}$ Compared to emission objectives, carbon budgets are more flexible and allow the social planner to reach the same climate target at lower cost.

A more systematic analysis is presented in Fig. 5. It gives the optimal entry dates of both measures (cheap and deep), as a function of the 2050 emission target. It shows that below a threshold emission target, the optimal strategy starts to implement the expensive, inert and high-abating potential measure before the cheap one. In our example, this happens when the emission target is lower than $2.25 \mathrm{GtCO}_{2} / \mathrm{yr}$ - i.e. when the abatement objective is higher than $2.75 \mathrm{GtCO}_{2} / \mathrm{yr}$.

The optimal strategy to achieve an emission target is not to set a growing carbon price and to implement sequentially the abatement options that show an abatement cost below this carbon price. ${ }^{9}$ However, if the government cannot credibly commit to long-term carbon prices (Kydland and Prescott, 1977; Dixit and Lambertini, 2003), investors may be left with only current prices to take their decisions. In this case, a carbon price of $60 \$ / \mathrm{tCO}_{2}$ would be necessary in 2006 to trigger the entry of deep (Fig. 4). This high carbon price would also trigger the implementation of cheap (because its abatement cost, $30 \$ / \mathrm{tCO}_{2}$, is lower than the signal) in 2006, i.e. too soon, leading to a suboptimal abatement

\footnotetext{
7 Since cumulative emissions are good proxies for climate change, both simulations would lead to comparable climate change impacts.

8 In other words, $390 \mathrm{G} \$$ is the lowest possible cost to reach the carbon budget constraint, while $630 \mathrm{G} \$$ is the lowest cost for reaching the same carbon budget through one aggregate emission target in 2050.

9 This corroborates previous findings that in presence of inertia, efforts to reduce emissions should not be equal to the carbon price at each point in time (Vogt-Schilb et al., 2013; Rozenberg et al., 2013).
} 


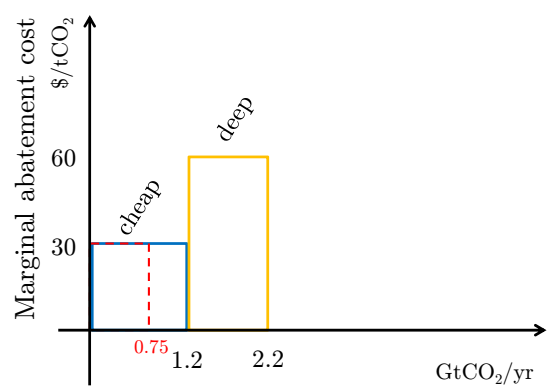

(a) Abatement potential by 2020

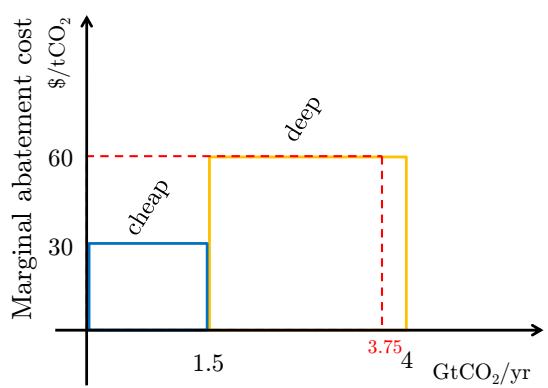

(b) Abatement potential by 2050

\begin{tabular}{lcccc}
\hline & & & Cheap & Deep \\
\hline Time Horizon & $t_{1}$ & $\mathrm{yr}$ & \multicolumn{2}{c}{20} \\
Achievable potential & $\tilde{A}$ & $\mathrm{GtCO}_{2} / \mathrm{yr}$ & 1.2 & 1.0 \\
\hline Time Horizon & $t_{2}$ & $\mathrm{yr}$ & \multicolumn{2}{c}{50} \\
Achievable potential & $\tilde{A}$ & $\mathrm{GtCO}_{2} / \mathrm{yr}$ & 1.5 & 2.5 \\
\hline
\end{tabular}

Figure 6: MACCs derived from our numerical values, using the achievable-potential approach. We explain why the 2020 target should not be reached by implementing only cheap.

pathway. In the conclusion we discuss possible solutions to this problem.

\subsection{The influence of long-term objectives on short-term strategies}

Actual policies include shorter-term emission objectives, such as the 2020 target in the EU. They are milestones toward a more ambitious climate target in the long run, as the $-75 \%$ by 2050 objective in Europe. In this section, we find that it is dangerous to use only information on costs and achievable potential to decide which measures to implement in order to achieve an intermediate target (Fig 6), because it can make the long term target impossible to reach.

We compare two simulations. The first simulation, labeled SO (Short-term Only), has a short-term constraint but no long-term constraint.

$$
E_{1}^{o b j}=E(2020)=4.25 \mathrm{GtCO}_{2} / \mathrm{yr}
$$

This target corresponds to $750 \mathrm{MtCO}_{2} / \mathrm{yr}$ abated in 2020, that is exactly the abatement achieved in 2020 in the optimal pathway to a $-75 \%$ in 2050 target according to our model (Fig. 4).

The second simulation, S\&L (Short-term and Long-term objectives), has the same short-term constraint for 2020, but takes into account the longer-term target: a reduction by $75 \%$ of GHG emissions in 2050. In this simulation, there are thus two emission milestones (see Eq. 9).

$$
\begin{aligned}
& E_{1}^{o b j}=E(2020)=4.25 \mathrm{GtCO}_{2} / \mathrm{yr} \\
& E_{2}^{o b j}=E(2050)=1.25 \mathrm{GtCO}_{2} / \mathrm{yr}
\end{aligned}
$$

Our objective is to assess the difference over the short-term between a strategy aiming at a short-term target and a strategy aiming at both short-term 


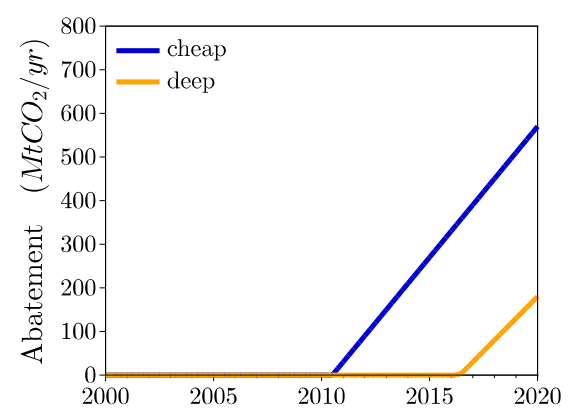

(a) Short-term Only

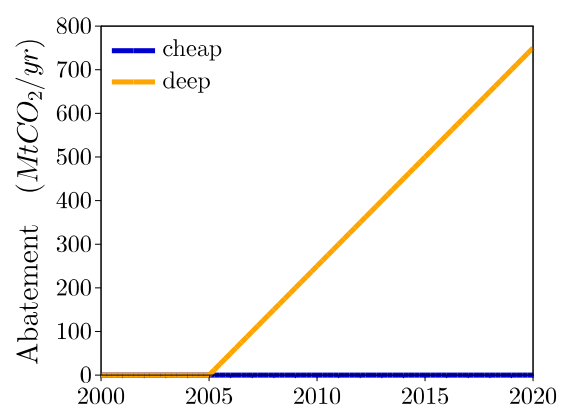

(b) Short-term and Long-term objs

Figure 7: Comparison of optimal abatement strategies to reach the same target for 2020, disregarding or taking into account the longer-term 2050 objective (respectively SO and S\&L). The best strategy to reach the 2020 target depends on whether this target is the ultimate objective ( $\mathrm{SO}$ ) or only a milestone towards a longer-term target (SL).

and long-term targets. We find that long-term objectives impact strongly the short-term strategy.

Figure 7 compares the optimal abatement strategies from 2000 to 2020 in the two cases. With both the 2020 and the 2050 objectives (simulation S\&L, panel a), the social planner starts by implementing deep in 2006, and does not implement cheap before 2020 (as in Section 5.1). In contrast, when the 2050 milestone is disregarded (simulation SO, panel b), the social planner starts abating later (in 2010 vs 2006) and uses cheaper and lower-potential options, namely cheap and deep instead of deep only. The discounted expenditures in abatement measures amounts to $28 \mathrm{G} \$$ against $112 \mathrm{G} \$$ when the 2050 objective is taken into account: the optimal short-term financial effort is much higher if the long-term target is taken into account, even though the abatement in $\mathrm{MtCO}_{2}$ is the same.

If the 2050 target was not taken into account before 2020, it may then appear extremely costly or even impossible to achieve. In this illustrative example, the $75 \%$ reduction in emissions becomes indeed impossible to achieve in $2050 .{ }^{10}$

Despite short-term aggregate emissions being reduced to the same level in SO and in S\&L by 2020, the SO strategy produces a lock-in in a carbon intensive pathway that cannot be reversed in the second period. In other words, the optimal strategy to reach the 2020 target is different (it uses more expensive options) if it's a milestone to a 2050 target than if it is the ultimate target. With an ambitious long-term objective, the short-term target needs to be achieved implementing the options with the largest potentials and the greatest inertia, not with the cheapest solutions.

In the previous subsection, we concluded that a unique price instrument may

10 Cheap has entered in 2006. It would reach its full potential $(1.5 \mathrm{Gt} / \mathrm{yr})$ in 2030 . If deep enters in 2021, it would also reach abatement of $1.5 \mathrm{Gt} / \mathrm{yr}$ in 2050,30 years after $(30 \mathrm{yr}$ $\left.\times 50 \mathrm{MtCO}_{2} / \mathrm{yr}\right)$. The total would be abatement of $3 \mathrm{Gt} / \mathrm{yr}$ in 2050 , when the target is $3.75 \mathrm{Gt} / \mathrm{yr}$ 
not be the best approach to trigger the right investments in emission-reduction measures, provided that actors may not rely on long-term signals. The same warning applies to aggregate emission targets.

Short-term targets are a priori relevant, because there is visibility over the short term on technology availability, macroeconomics trends and institutional frameworks. For instance, they can be enforced with tradable emissions permits, such as the EU ETS system. However, if decision makers omit the longer-term target when deciding which measures can be implemented to reach the shortterm target, they will focus on the cheapest available options (Fig. 6a and 7a).

It is therefore a good practice to announce long-term objectives along with short-term binding policies. An example are the existing carbon-intensity or fuel-efficiency standards for new passenger vehicles (ICCT, 2012): governments have enacted short-term standards (e.g. $130 \mathrm{~g} / \mathrm{km}$ in 2015 in Europe), and also enacted or proposed longer-term ones (95 g/km in 2020 in Europe).

This result also sheds a new light on sector-specific mitigation targets, such as energy-efficiency standards in the automobile sector or the $20 \%$ renewable power in the European Union. This kind of sectoral short-term targets in favor of expensive but high-potential technologies may be a way to ensure that aggregate targets (the $20 \%$ reductions of greenhouse gas emissions) are not reached using only the cheapest options (as coal-to-gas switch).

\section{Conclusion}

This paper investigates the design of optimal abatement strategies using information on the cost, the abating potential and the implementation speed of a set of available measures.

Optimal abatement strategies may (i) implement expensive options before the whole potential of cheaper measures has been exploited; (ii) use expensive options even when cheap ones appear sufficient to meet the climate target; or (iii) start to implement some expensive options before cheaper ones. If the climate objective is stringent and inertia is large, the optimal strategy would be to start implementing at the same time a set of measures covering a wide range of abatement costs.

Our results have policy and methodological implications. In the European Union, there was a debate on whether aggregate GHG emissions should be abated by $20 \%$ or $30 \%$ in the short-term (i.e. 2020). This question on when to abate GHG emissions should not be separated from the question on how these abatement have to be done (i.e., in which sector and with which measures). Economic actors might otherwise focus on cheap and fast-to-implement solutions to reach the short-term target, neglecting high-potential but high-inertia options required to meet an ambitious objective in 2050 (see also Rose et al., 1999; Sandén and Azar, 2005; Narain and Veld, 2008; del Rio Gonzalez, 2008).

The optimal approach to achieve an emission target is not to set a growing carbon price and to implement sequentially the abatement options that show an abatement cost below this carbon price. Decision makers need assessments of the speed at which various measures to curb greenhouse gas emissions can be implemented, and they should be informed of long-term objectives in advance. Further research could investigate how policies targeted at high-potential but long-to-implement options, such as urban planing or deployment of low-carbon 
technologies, may complement a carbon price in the absence of perfect foresight or long-term policy credibility.

There is of course a balance to maintain (Azar and Sandén, 2011): sectoral policies should be targeted enough to distinguish differences in inertia, but broad enough to let economic agents select the best options and technologies to reach them (this may be the case, for instance, of existing fuel economy standards in the auto industry). Because of information asymmetry and the risk of rent-seeking behavior, micro-managing mitigation by defining over-targeted objectives can be counter-productive (Laffont, 1999). Also, objectives need to be updated when new information is available (Rodrik, 2008); for instance if one measure turns out to be more expensive, or turns out to save less GHG, than expected. Finally, if sectoral policies overlap, they may come with additional costs (Braathen, 2007; Böhringer and Rosendahl, 2010) or benefits (Fischer and Preonas, 2010; Lecuyer and Quirion, 2013) that should be analyzed carefully and taken into account (Hallegatte et al., 2013).

Our results are based on illustrative examples. The main conclusion is methodological: we reinforce the need to account for sector-specific inertia when designing climate policies. To date, the literature has focused on cross-sector differences on knowledge spillovers (e.g. Manne and Richels, 2004; Rosendahl, 2004). While some numerical studies (Lecocq et al., 1998; Schwoon and Tol, 2006; Jaccard and Rivers, 2007) and integrated assessment models (Wilson et al., 2013) factor this type of differentiated inertias, the optimal timing and cost of emission reduction taking into account differentiated inertias is the object of only few theoretical contributions (e.g, Vogt-Schilb et al., 2012; Lecuyer and Vogt-Schilb, 2013).

Measure-explicit marginal abatement cost curves have proved extremely effective in communicating some results from the economics of climate mitigation to decision makers and the general public. For instance, by reporting the cost and potential of a list of mitigation measures, MACCs illustrate in a simple way why energy-efficiency is a key option: it can save significant amounts of GHG at a low or negative cost. Existing MAC curves, however, do not explain why more expensive options, such as carbon capture and storage or renewable power, should receive significant attention today. Our answer is that these options can abate large amounts of GHG in the future, and that they need time to be implemented (Grübler et al., 1999). The reporting currently carried out by MAC curves could be enhanced by supplying assessments of the cost, potential, and implementation speed of each option.

With this information, the optimal implementation schedule of the various existing abating options could be assessed in a simple, transparent and accessible process, for instance using linear models like the one proposed in this paper. Such a model certainly is less sophisticated than state-of-the-art integrated assessment models, but can prove nonetheless useful for researchers from other fields, decision makers, and the general public. This process would also provide figures to debate new or existing sectoral policies, such as the objective of $20 \%$ of renewable energies in Europe by 2020, the fuel economy standards in the auto industry, or proposed changes in land-use planning, building norms and infrastructure design. 


\section{Acknowledgments}

We thank Nils Axel Braathen, Patrice Dumas, Marianne Fay, Michael Grubb, Céline Guivarch, Jean Charles Hourcade, Fabian Kesicki, Camille Mazas, Guy Meunier, Julie Rozenberg, anonymous referees, the audiences at the International Energy Workshop, at the European Association of Environmental and Resource Economists Conference, at the International Association of Energy Economics and at the CIRED seminar who provided useful comments. We also thank Patrice Dumas for technical support. The remaining errors are entirely the authors'. Financial support from the Institut pour la Mobilité Durable, from École des Ponts ParisTech, and from ESMAP (the World Bank). The views expressed in this paper are the sole responsibility of the authors. They do not necessarily reflect the views of the World Bank, its executive directors, or the countries they represent.

\section{References}

Agarwal, R., Bayus, B. L., 2002. The market evolution and sales takeoff of product innovations. Management Science 48 (8), 1024-1041.

Allen, M. R., Frame, D. J., Huntingford, C., Jones, C. D., Lowe, J. A., Meinshausen, M., Meinshausen, N., 2009. Warming caused by cumulative carbon emissions towards the trillionth tonne. Nature 458 (7242), 1163-1166.

Ambrosi, P., Hourcade, J., Hallegatte, S., Lecocq, F., Dumas, P., Ha Duong, M., 2003. Optimal control models and elicitation of attitudes towards climate damages. Environmental Modeling and Assessment 8 (3), 133-147.

Azar, C., Sandén, B. A., 2011. The elusive quest for technology-neutral policies. Environmental Innovation and Societal Transitions 1 (1), 135-139.

Beaumont, N. J., Tinch, R., 2004. Abatement cost curves: a viable management tool for enabling the achievement of win-win waste reduction strategies? Journal of Environmental Management 71 (3), 207-215.

Böhringer, C., Rosendahl, K. E., 2010. Green promotes the dirtiest: on the interaction between black and green quotas in energy markets. Journal of Regulatory Economics 37 (3), 316-325.

Bloomberg, 2010. A fresh look at the cost of reducing U.S. carbon emissions. Carbon Markets-North America- Research Note.

Braathen, N. A., 2007. Instrument mixes for environmental policy: How many stones should be used to kill a bird? International Review of Environmental and Resource Economics 1 (2), 185-235.

Brook, A., Kendrick, D., Meeraus, A., 1988. GAMS, a user's guide. SIGNUM Newsl. 23 (3-4), 10-11, ACM ID: 58863.

Davis, S. J., Caldeira, K., Matthews, H. D., 2010. Future CO2 emissions and climate change from existing energy infrastructure. Science 329 (5997), 1330 -1333.

DECC, 2011. Impact assessment of fourth carbon budget level. Impact Assessment DECC0054, Department of Energy and Climate Change, UK.

del Rio Gonzalez, P., 2008. Policy implications of potential conflicts between shortterm and long-term efficiency in CO2 emissions abatement. Ecological Economics 65 (2), 292-303. 
Dixit, A., Lambertini, L., 2003. Interactions of commitment and discretion in monetary and fiscal policies. The American Economic Review 93 (5), pp. 1522-1542.

Enkvist, P., Nauclér, T., Rosander, J., 2007. A cost curve for greenhouse gas reduction. McKinsey Quarterly 1, 34.

ESMAP, 2012. Planning for a low carbon future: Lessons learned from seven country studies. Knowledge series 011/12, Energy Sector Management Assistance Program - The World Bank, Washington DC, USA.

Fischer, C., Preonas, L., 2010. Combining policies for renewable energy: Is the whole less than the sum of its parts? International Review of Environmental and Resource Economics 4, 51-92.

Grübler, A., Nakićenović, N., Victor, D. G., 1999. Dynamics of energy technologies and global change. Energy policy 27 (5), 247-280.

Guivarch, C., Hallegatte, S., 2011. Existing infrastructure and the $2 \mathrm{C}$ target. Climatic Change 109 (3-4), 801-805.

Hallegatte, S., Fay, M., Vogt-Schilb, A., 2013. Green industrial policies: When and how. World Bank Policy Research Working Paper (6677).

ICCT, 2012. How vehicle standards and fuel fees can cut CO2 emissions and boost the economy. Policies That Work 2, International Council on Clean Transportation, Washington DC.

IEA, 2009. Transport Energy and CO2 : Moving towards Sustainability. Organisation for Economic Co-operation and Development,, Paris, France.

IPCC, 2007. Summary for policymakers. In: Climate change 2007: Mitigation. Contribution of working group III to the fourth assessment report of the intergovernmental panel on climate change. Cambridge University Press, Cambridge, UK and New York, USA.

Jaccard, M., Rivers, N., 2007. Heterogeneous capital stocks and the optimal timing for CO2 abatement. Resource and Energy Economics 29 (1), 1-16.

Jackson, T., 1991. Least-cost greenhouse planning supply curves for global warming abatement. Energy Policy 19 (1), 35-46.

Kesicki, F., 2012a. Intertemporal issues and marginal abatement costs in the UK transport sector. Transportation Research Part D: Transport and Environment 17 (5), 418-426.

Kesicki, F., 2012b. Marginal abatement cost curves: Combining energy system modelling and decomposition analysis. Environmental Modeling \& Assessment.

Kesicki, F., Ekins, P., 2012. Marginal abatement cost curves: a call for caution. Climate Policy 12 (2), 219-236.

Klepper, G., Peterson, S., 2006. Marginal abatement cost curves in general equilibrium: The influence of world energy prices. Resource and Energy Economics 28 (1), 1-23.

Kuik, O., Brander, L., Tol, R. S., 2009. Marginal abatement costs of greenhouse gas emissions: A meta-analysis. Energy Policy 37 (4), 1395-1403.

Kydland, F. E., Prescott, E. C., 1977. Rules rather than discretion: The inconsistency of optimal plans. Journal of Political Economy 85 (3), pp. 473-492. 
Laffont, J.-J., 1999. Political economy, information, and incentives. European Economic Review 43, 649-669.

Lecocq, F., Hourcade, J., Ha Duong, M., 1998. Decision making under uncertainty and inertia constraints: sectoral implications of the when flexibility. Energy Economics 20 (5-6), 539-555.

Lecuyer, O., Quirion, P., 2013. Can uncertainty justify overlapping policy instruments to mitigate emissions? Ecological Economics 93, 177-191.

Lecuyer, O., Vogt-Schilb, A., 2013. Assessing and ordering investments in polluting fossil-fueled and zero-carbon capital. Cired Working Paper (49-2013).

Manne, A., Richels, R., 2004. The impact of learning-by-doing on the timing and costs of CO2 abatement. Energy Economics 26 (4), 603-619.

Mansfield, E., 1998. Academic research and industrial innovation: An update of empirical findings. Research policy 26 (7), 773-776.

Matthews, H. D., Gillett, N. P., Stott, P. A., Zickfeld, K., 2009. The proportionality of global warming to cumulative carbon emissions. Nature 459 (7248), 829-832.

McKinsey, 2009. Charting our water future: Economic frameworks to inform decisionmaking. Tech. rep., McKinsey \& Company.

McKinsey, 2009. Pathways to a low-carbon economy: Version 2 of the global greenhouse gas abatement cost curve. Tech. rep., McKinsey \& Company.

Meunier, G., Finon, D., 2013. Option value in low-carbon technology policies. Climate Policy 13 (1), 1-19.

Morris, J., Paltsev, S., Reilly, J., 2011. Marginal abatement costs and marginal welfare costs for greenhouse gas emissions reductions: Results from the EPPA model. Environmental Modeling \& Assessment 17 (4), 325-336.

Narain, U., Veld, K., 2008. The clean development mechanism's low-hanging fruit problem: When might it arise, and how might it be solved? Environmental and Resource Economics 40 (3), 445-465.

Rodrik, D., 2008. Normalizing industrial policy. Commission for Growth and Development. Working Paper 3, World Bank.

Rose, A., Bulte, E., Folmer, H., 1999. Long-run implications for developing countries of joint implementation of greenhouse gas mitigation. Environmental and Resource Economics 14 (1), 19-31.

Rosendahl, K. E., 2004. Cost-effective environmental policy: implications of induced technological change. Journal of Environmental Economics and Management 48 (3), 1099-1121.

Rozenberg, J., Vogt-Schilb, A., Hallegatte, S., 2013. How capital-based instruments facilitate the transition toward a low-carbon economy: a tradeoff between optimality and acceptability. World Bank Policy Research Working Paper (6609).

Rubin, E. S., Cooper, R. N., Frosch, R. A., Lee, T. H., Marland, G., Rosenfeld, A. H., Stine, D. D., 1992. Realistic mitigation options for global warming. Science 257 (5067), 148-149. 
Sandén, B. A., Azar, C., 2005. Near-term technology policies for long-term climate targets - economy wide versus technology specific approaches. Energy Policy 33 (12), $1557-1576$

Schwoon, M., Tol, R. S., 2006. Optimal CO2-abatement with socio-economic inertia and induced technological change. The Energy Journal 27 (4).

Scilab Consortium, 2011. Scilab: The free software for numerical computation. Scilab Consortium, Paris, France.

Stoft, S. E., 1995. The economics of Conserved-Energy "Supply" curves. The Energy Journal 16 (4), 109-140.

Sweeney, J., Weyant, J., 2008. Analysis of measures to meet the requirements of California's Assembly Bill 32. Tech. rep., Stanford University.

Vogt-Schilb, A., Meunier, G., Hallegatte, S., 2012. How inertia and limited potentials affect the timing of sectoral abatements in optimal climate policy. World Bank Policy Research Working Paper 6154.

Vogt-Schilb, A., Meunier, G., Hallegatte, S., 2013. Should marginal abatement costs differ across sectors? The effect of low-carbon capital accumulation. World Bank Policy Research Working Paper 6415.

Wächter, P., 2013. The usefulness of marginal CO2-e abatement cost curves in Austria. Energy Policy.

Wilson, C., Grubler, A., Bauer, N., Krey, V., Riahi, K., 2013. Future capacity growth of energy technologies: are scenarios consistent with historical evidence? Climatic Change 118 (2), 381-395.

World Bank, International Finance Corporation, 2013. Doing business 2013: Smarter regulations for small and medium-sized enterprises. World Bank : International Finance Corporation, Washington, D.C.

Wuppertal Institute, 2006. Options and potentials for energy end-use efficiency and energy services. Tech. rep., Wuppertal Institute for Climate, Environment and Energy. 